\title{
ANÁLISES DOS EFEITOS ALELOPÁTICOS DE PLANTAS DANINHAS EM Cyperus rotundus
}

\section{Leonardo Gonçalves Vargas ${ }^{1}$ \\ André Alves Pinheiro ${ }^{2}$ \\ Gabriel Dias de Oliveira ${ }^{3}$ \\ Wilian Rodrigues Ribeiro ${ }^{4}$ \\ Leandro Pin Dalvi ${ }^{5}$}

Resumo: O estudo da alelopatia é de extrema importância para a agricultura, sendo possível solucionar problemas relacionados a danos na cultura com plantas invasoras que competem por nutrientes e liberam aleloquímicos, os quais podem causar danos a uma planta vizinha como patologias, ataque de insetos ou inibição de desenvolvimento. O objetivo deste trabalho foi avaliar os efeitos alelopáticos que a adubação verde contribui para o controle de Cyperus rotundus. Com base nesse conceito, procederam-se 4 tratamentos com 6 repetições cada e 1 testemunha, com as plantas daninhas em ponto de murcha com 2 semanas de crescimento em casa de vegetação. Foram realizadas aplicações com extratos de outras plantas daninhas como a Trapoeraba (Commelina benghalensis L.), a Losna Brava (Artemisia absinthium) e a Brachiaria (Brachiaria decumbens). Ao final do experimento pode-se observar o efeito alelopático benéfico em alguns tratamentos para a cultura da Cyperus rotundus (Tiririca).

Palavras-chave: Tiririca, Alelopatia, Cyperus rotundus.

\footnotetext{
1 Graduando em Agronomia da Universidade Federal do Espírito Santo - UFES, Brasil. E-mail: leonardoovargasufes@hotmail.com.

2 Graduando em Agronomia da Universidade Federal do Espírito Santo - UFES, Brasil. E-mail: aalvespinheiro7@gmail.com.

3 Graduando em Agronomia da Universidade Federal do Espírito Santo - UFES, Brasil. E-mail: gabriel.dias.oliveira@gmail.com.

4 Graduando em Agronomia da Universidade Federal do Espírito Santo - UFES, Brasil. E-mail: wilianrodrigues@msn.com.

5 Doutor e Professor da Universidade Federal do Espírito Santo - UFES, Brasil. E-mail: leandropin@yahoo.com.br.
} 